\title{
Time-dependent effect in green synthesis of silver nanoparticles
}

\author{
This article was published in the following Dove Press journal: \\ International Journal of Nanomedicine \\ I April 201 I \\ Number of times this article has been viewed
}

\author{
Majid Darroudi',2 \\ Mansor Bin Ahmad ${ }^{3}$ \\ Reza Zamiri ${ }^{4}$ \\ AK Zak ${ }^{5}$
}

\section{Abdul Halim Abdullah',3 \\ Nor Azowa Ibrahim ${ }^{3}$ \\ 'Advanced Materials and \\ Nanotechnology Laboratory, Institute \\ of Advanced Technology (ITMA), \\ Universiti Putra Malaysia, Selangor, \\ Malaysia; '2Department of Chemistry, \\ Faculty of Science, Ferdowsi \\ University of Mashhad, Mashhad, \\ Iran; ${ }^{3}$ Department of Chemistry, \\ ${ }^{4}$ Department of Physics, Faculty of \\ Science, Universiti Putra Malaysia, \\ Selangor, Malaysia; ${ }^{5}$ Low Dimensional \\ Materials Research Center, \\ Department of Physics, Faculty of \\ Science, University of Malaya, Kuala \\ Lumpur, Malaysia}

Correspondence: Majid Darroudi

Advanced Materials and Nanotechnology

Laboratory, Institute of Advanced

Technology (ITMA), Universiti Putra

Malaysia, 43400 UPM Serdang,

Selangor, Malaysia

Tel +60389466044

Fax +60389466043

Email majiddarroudi@gmail.com
Abstract: The application of "green" chemistry rules to nanoscience and nanotechnology is very important in the preparation of various nanomaterials. In this work, we successfully developed an eco-friendly chemistry method for preparing silver nanoparticles (Ag-NPs) in natural polymeric media. The colloidal Ag-NPs were synthesized in an aqueous solution using silver nitrate, gelatin, and glucose as a silver precursor, stabilizer, and reducing agent, respectively. The properties of synthesized colloidal Ag-NPs were studied at different reaction times. The ultraviolet-visible (UV-vis) spectra were in excellent agreement with the obtained nanostructure studies performed by transmission electron microscopy (TEM) and their size distributions. The prepared samples were also characterized by X-ray diffraction (XRD) and atomic force microscopy (AFM). The use of eco-friendly reagents, such as gelatin and glucose, provides green and economic attributes to this work.

Keywords: silver nanoparticles, gelatin, green chemistry, time-dependent effect, ultravioletvisible spectra

\section{Introduction}

Nanomaterials have received much attention because their structure and properties differ significantly from those of atoms, molecules, and bulk materials. ${ }^{1}$ The synthesis of metal nanoparticles has been widely discussed in the literature due to their unique physical and chemical properties, which have many potential applications. ${ }^{2-4}$ The use of inexpensive chemicals and non-toxic solvents - environmentally friendly and renewable/ biodegradable - are central to materials synthesis and processing, considering the green nature of these strategies. The reducing agent, reaction medium, and stabilizer are three key factors in the synthesis and stabilization of metallic nanoparticles. ${ }^{5}$

Natural polymers such as gelatin, chitosan, proteins, and starch are all interesting materials for medical applications because they are biodegradable and bioabsorbable with degradation products that are non-toxic. ${ }^{6}$ Gelatin is a natural biopolymer extracted from the partial hydrolysis of collagen which has good biocompatibility and biodegradability, and has been widely used in wound dressings, drug carriers, and tissue scaffolds in recent years. ${ }^{7}$ There are many methods for synthesizing metal nanoparticles, including photo reduction, ${ }^{8}$ laser ablation, ${ }^{9}$ chemical reduction in aqueous media with different polymer surfactants, ${ }^{10,11}$ reduction of chemicals in soft matrices, ${ }^{12-14}$ reduction of chemicals in solid matrices (eg, mesoporous silicate) ${ }_{1}^{15}$ and chemical vapor deposition. ${ }^{16}$ Silver nanoparticles (Ag-NPs) are widely used as catalysts, ${ }^{17-19}$ photo-catalysts, ${ }^{20-22}$ and in surface-enhanced Raman spectroscopy ${ }^{24-26}$ as well as chemical analysis. ${ }^{27}$ 
The use of gelatin as a capping agent and glucose as a reducing agent to synthesize Ag-NPs in aqueous solutions is attractive because organic solvents are not used and no corresponding pollutants are made; moreover, the resulting nanoparticles in gelatin matrix are biologically compatible. The main objective of this work is to apply the principles of green chemistry ${ }^{28}$ in the synthesis of Ag-NPs, such as when using an eco-stabilizer and reducing agent. The synthesis method presented could be useful in providing an economic method for the industrial preparation of highly monodispersed, biocompatible, and stable colloidal Ag-NPs. The smallest nanoparticles of about $5 \mathrm{~nm}$ having totally monodispersity could be obtained. Other advantages of this approach include the physical conditions of the synthesis, such as the moderate preparation temperature, the lack of need for an additional flow of inert gas, and the use of atmospheric pressure.

\section{Experimental}

All reagents in this work were analytical-grade and were used as received without further purification. $\mathrm{AgNO}_{3}$ (99.98\%) was used as a silver precursor, and was provided by Merck, Germany. Gelatin (type B) was used as a stabilizer for the preparation of Ag-NPs and was purchased from Sigma-Aldrich, MO, USA. D-Glucose was used as a reducing agent for the reduction of silver ions to $\mathrm{Ag}$ atoms and was obtained from BDH Chemical Ltd., Poole, UK. All solutions were freshly prepared using double distilled water and kept in the dark to avoid any photochemical reactions. All glassware used in experimental procedures were cleaned in a fresh solution of $\mathrm{HNO}_{3} / \mathrm{HCl}(3: 1, \mathrm{v} / \mathrm{v})$, washed thoroughly with double distilled water, and dried before use.

For synthesis of Ag-NPs, $2.0 \mathrm{~g}$ gelatin was added to $190 \mathrm{~mL} \mathrm{H}_{2} \mathrm{O}$ in a flask, and the solution was stirred and heated at $40^{\circ} \mathrm{C}$ to obtain a clear solution. To obtain the $\mathrm{Ag}^{+} /$ gelatin solution, the silver solution $(10 \mathrm{~mL}, 1 \mathrm{M})$ was added to the gelatin solution with continuous stirring. Then, $20 \mathrm{~mL}$ of glucose solution ( $2 \mathrm{M}$ ) was added to the $\mathrm{Ag}^{+} /$gelatin solution. The solution obtained was distributed into 5 cuvettes, and the prepared solutions were stirred and maintained for different periods of time: 1 (S1), 3 (S2), 6 (S3), 24 (S4), and 48 hours (S5), respectively. Throughout the reduction process, all solutions were kept at a temperature of $60^{\circ} \mathrm{C}$ in the dark to avoid any photochemical reactions.

The prepared colloidal Ag-NPs were characterized by using ultraviolet-visible (UV-vis) spectroscopy, X-ray diffraction (XRD), transmission electron microscopy

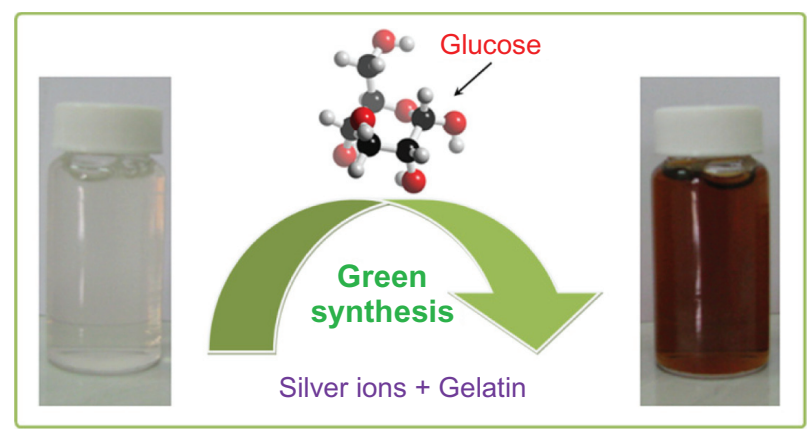

Scheme I Photography scheme of the colloidal silver nanoparticles synthesized in aqueous gelatin solution.

(TEM), and atomic force microscopy (AFM). To ensure the formation of nanosilver, the particles were tested for their optical absorption property using a Lambda 35-Perkin Elmer UV-vis spectrophotometer over the range of 300 to $700 \mathrm{~nm}$. The crystalline structure of Ag-NPs was characterized with an XRD (Philips, X'pert, $\mathrm{Cu} \mathrm{K}_{\alpha}$ ). The XRD patterns were scanned at a speed of $2 \% \mathrm{~min}$. The AFM experiments were carried out on an Ambios-Q scope (SPM) machine. TEM observations were performed with a Hitachi H-7100 electron microscopy, and the particle size distributions were determined using UTHSCSA Image Tool software (Ver. 3.00).

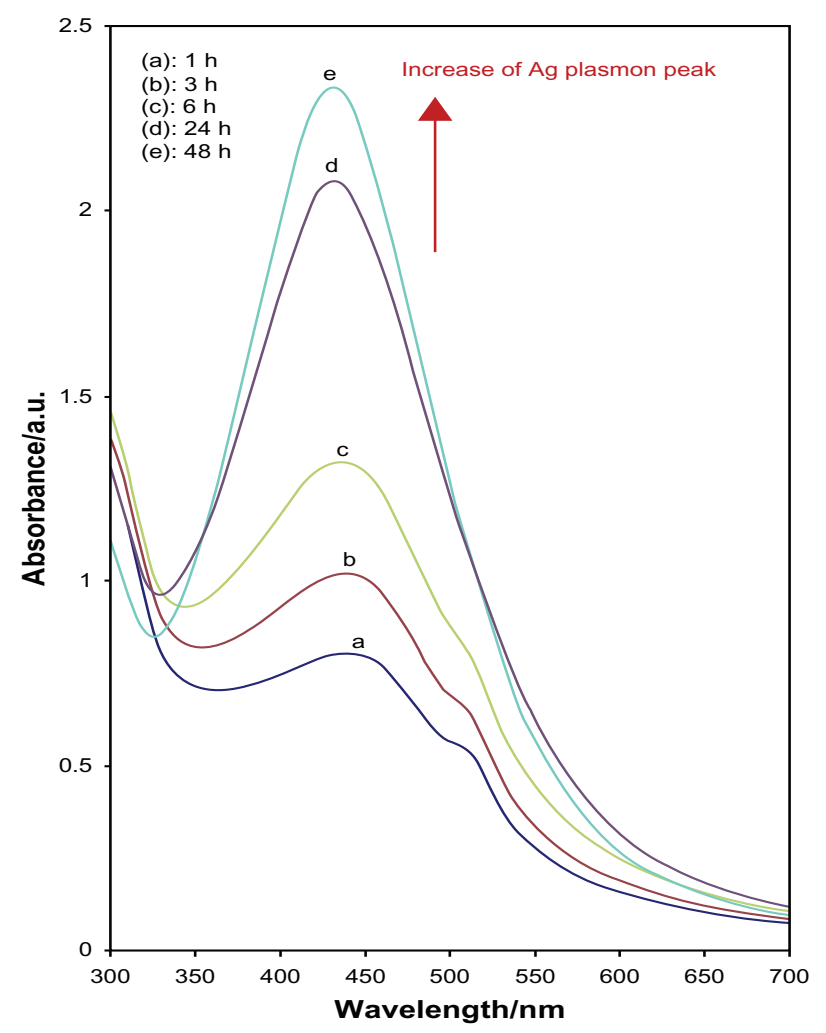

Figure I The UV-vis absorption spectra of the colloidal Ag-NPs synthesized using glucose at different reaction times.

Abbreviations: Ag-NPs, silver nanoparticles; UV-vis, ultraviolet visible. 
A

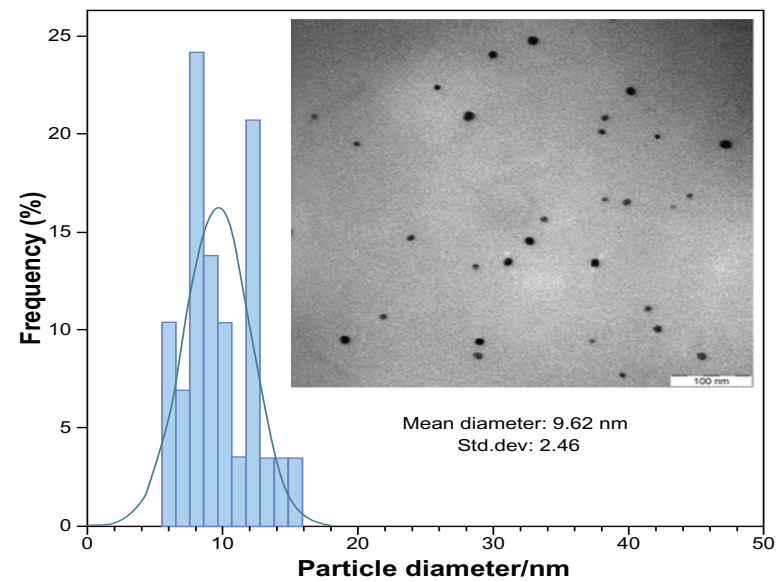

B

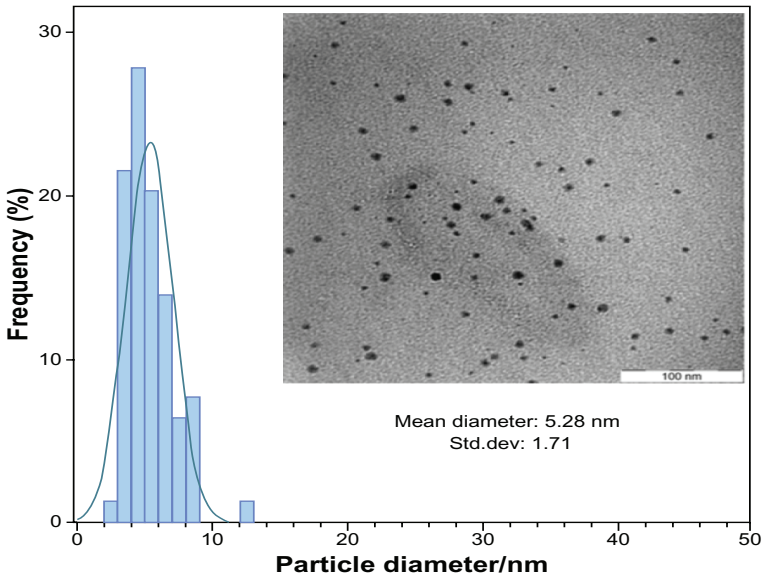

Figure 2 The typical TEM images and corresponding particles size distribution of Ag-NPs at different reaction times; A) S3 and B) S5. Abbreviations: Ag-NPs, silver nanoparticles; TEM, transmission electron microscopy.

\section{Results and discussion}

The color of $\mathrm{Ag}^{+} / \mathrm{gel}$ solutions over different periods of time gradually changed from colorless to light brown, then to brown, and finally dark brown, indicating the formation of Ag-NPs in the gelatin solution (Scheme 1). Glucose, as an aldehyde, was able to reduce $\mathrm{Ag}^{+}$ions to $\mathrm{Ag}^{0}$, and through this reaction, glucose can be oxidized to gluconic acid. The gradual formation of Ag-NPs was investigated by UV-vis spectroscopy, which has proven to be a useful spectroscopic method for the detection of prepared NPs over time. In UV-vis spectra, the Ag-NPs can be shown by a surface plasmon resonance (SPR) peak at around $400 \mathrm{~nm}$, but a small shift (blue-shift or red-shift) in the wavelength of the peak could be related to obtaining Ag-NPs in different shapes, sizes, or solvent dependences of prepared Ag-NPs.

After reaction at $60^{\circ} \mathrm{C}$ for 1 hour, the Ag-NPs obtained showed a UV-vis absorption peak, a characteristic SPR band for Ag-NPs, centered at $400 \mathrm{~nm}$ (Figure 1A). As shown in Figure 1, the intensity of the SPR peak increased as the reaction time increased, which indicated the continued reduction of the silver ions, and the increase of the absorbance with the reaction time indicates that the concentration of Ag-NPs increases. ${ }^{29}$ When the reaction time reached 3 hours (Figure 1B) the absorbance was increased, and the $\lambda_{\text {max }}$ value was slightly blue-shifted to $438 \mathrm{~nm}$. For reaction times of 6 (Figure 1C) and 24 hours (Figure 1D), the absorbance was also increased and blue-shifted to 435 and $431 \mathrm{~nm}$, respectively. This phenomenon indicated that the size of particles was decreased because the absorbance peak due to the SPR of metal nanoparticles shows the blue-shift with decreasing particle size. ${ }^{30}$ At the end of the reaction (48 hours, Figure 1E), the absorbance was considerably increased and there was no significant change in $\lambda_{\text {max }}$ value ( $430 \mathrm{~nm}$ ), compared with the 24 hour reaction time. At the initial stage of the reaction, the Ag-NPs formed with a broad size distribution, which led to a SPR peak at about $440 \mathrm{~nm}$. After this stage, the Ag-NPs could dissociate due to heating to form smaller particles stabilized by the amine pendant groups on the gelatin, which leads to the formation of gelatin-stabilized stable Ag-NPs. ${ }^{31}$ The TEM images demonstrate the formation of Ag-NPs at different periods of time. Figure 2 shows typical TEM images and the corresponding particle size distribution of the prepared Ag-NPs at different times. The TEM results indicate that the samples obtained over a longer time period retained a narrower particle size distribution; the average size of all prepared Ag-NPs was $<20 \mathrm{~nm}$; and a smaller average size (about $5 \mathrm{~nm}$ ) was obtained for S5.

Figure 3 shows the XRD patterns of Ag-NPs formed in S5, which indicates the formation of the silver crystalline structure. The XRD peaks at $2 \theta$ degrees of $38.1,44.3$, 64.5, and 77.5 can be attributed to the (111), (200), (220), and (311) crystalline planes of face-centered-cubic (fcc) crystalline structure of metallic silver, respectively (JCPDS file no. 00-004-0783). The AFM result shows the surface

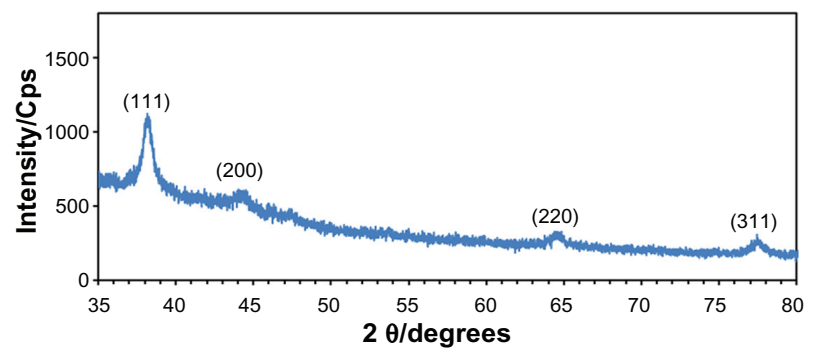

Figure 3 The XRD pattern of prepared Ag-NPs (S5).

Abbreviation: Ag-NPs, silver nanoparticles; Cps, Counts per second; XRD, X-ray diffraction 

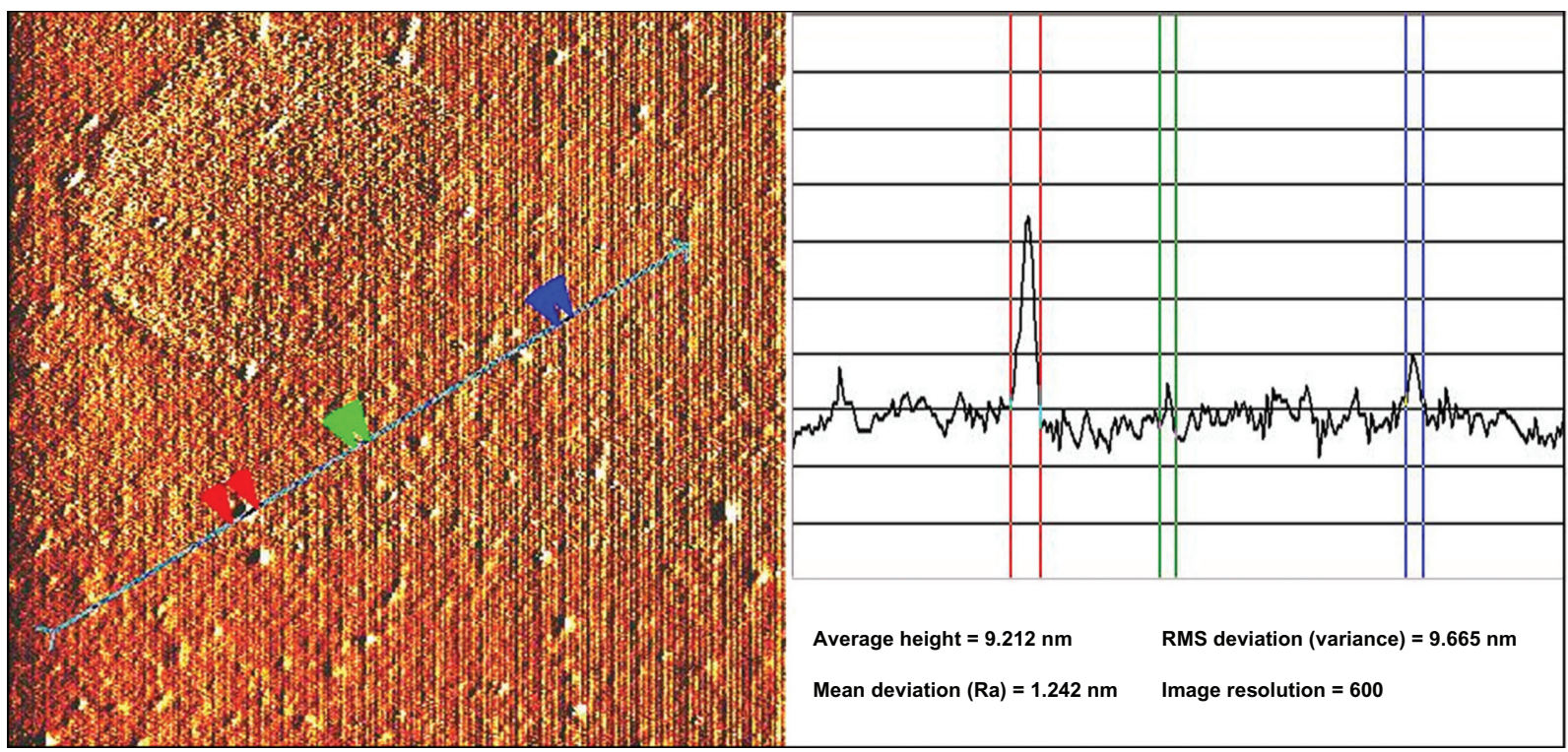

Figure 4 The AFM image of prepared Ag-NPs (S5)

Abbreviations: AFM, atomic force microscopy; Ag-NPs, silver nanoparticles; Ra, arithmetic mean of surface roughness; RMS, root mean square.

morphology of the well-dispersed Ag-NPs formed in gelatin media. As observed in Figure 4, the value determined by the AFM was close to the TEM determined, and the films of gelatin containing Ag-NPs displayed a densely uniform packed structure. Thus, the Ag-NPs-gelatin films could provide a biocompatible and rough surface for special biological applications, such as cell immobilization.

\section{Conclusion}

We have described a simple and eco-friendly time-dependent method to synthesize colloidal Ag-NPs in corresponding metal solution using green agents, which requires no special physical conditions. The Ag-NPs obtained in this work are uniform and have a narrow particle size distribution, with a small average particle diameter of about $5 \mathrm{~nm}$. This preparation method is general and may be extended to other noble metals, such as $\mathrm{Au}, \mathrm{Pd}$, and $\mathrm{Pt}$, and may possibly find various additional medicinal, industrial, and technological applications.

\section{Disclosure}

The authors disclose no conflicts of interest.

\section{References}

1. Rosei F. Nanostructured surfaces: challenges and frontiers in nanotechnology. J Phys Condens Matter. 2004;16:S1373-S1436.

2. Papp S, Patakfalvi R, Dekany I. Metal nanoparticle formation on layer silicate lamellae. Colloid Polym Sci. 2008;286:3-14.

3. Chimentao RJ, Medina F, Sueiras JE, Fierro JLG, Cesteros Y, Salagre P. Effects of morphology and cesium promotion over silver nanoparticles catalysts in the styrene epoxidation. J Mater Sci. 2007;42:3307-3314.
4. Chen D, Qiao X, Qiu X, Chen J. Synthesis and electrical properties of uniform silver nanoparticles for electronic applications. J Mater Sci. 2009;44:1076-1081.

5. Liu J, He F, Gunn TM, Zhao D, Roberts CB. Precise seed-mediated growth and size-controlled synthesis of palladium nanoparticles using a green chemistry approach. Langmuir. 2009;25:7116-7128.

6. Mozafari MR. Nanomaterials and Nanosystems for Biomedical Applications. Dordrecth, The Netherlands: Springer; 2007.

7. Xu X, Zhou M. Antimicrobial gelatin nanofibers containing silver nanoparticles. Fiber Polym. 2008;9:685-690.

8. Darroudi M, Ahmad MB, Shameli K, Abdullah AH, Ibrahim NA. Synthesis and characterization of UV-irradiated silver/montmorillonite nanocomposites. Solid State Sci. 2009;11:1621-1624.

9. Darroudi M, Ahmad MB, Zamiri R, et al. Preparation and characterization of gelatin mediated silver nanoparticles by laser ablation. J Alloy Compd. 2011;509:1301-1304

10. Aihara N, Torigoe K, Esumi K. Preparation and characterization of gold and silver nanoparticles in layered laponite suspensions. Langmuir. 1998; 14:4945-4949.

11. Lin XZ, Teng X, Yang H. Direct synthesis of narrowly dispersed silver nanoparticles using a single-source precursor. Langmuir. 2003;19: 10081-10085

12. Zhuang X, Cheng B, Kang W, Xu X. Electrospun chitosan/gelatin nanofibers containing silver nanoparticles. Carbohydr Polym. 2010;82: 524-527.

13. Darroudi M, Ahmad MB, Abdullah AH, Ibrahim NA, Shameli K. Effect of accelerator in green synthesis of silver nanoparticles. Int J Mol Sci. 2010;11:3898-3905.

14. Hebeish AA, El-Rafie MH, Abdel-Mohdy FA, Abdel-Halimand ES, Emam HE. Carboxymethyl cellolose for green synthesis and stabilization of silver nanoparticles. Carbohydr Polym. 2010;82:933-941.

15. Dag O, Samarskaya O, Coombs N, Ozin GA. The synthesis of mesostructured silica films and monoliths functionalised by noble metal nanoparticles. J Mater Chem. 2003;13:328-334.

16. Szłyk E, Piszczek P, Grodzicki A, et al. CVD of Ag-I complexes with tertiary phosphines and perfluorinated carboxylates-A new class of silver precursors. Chem Vapor Depos. 2001;7:111-116.

17. Chimentao RJ, Kirm I, Medina F, et al. Sensitivity of styrene oxidation reaction to the catalyst structure of silver nanoparticles. Appl Surf Sci. 2005;252:793-800. 
18. Jiang ZJ, Liu CY, Sun LW. Catalytic properties of silver nanoparticles supported on silica spheres. J Phys Chem B. 2005;109:1730-1735.

19. Yan J, Tao H, Zeng M, et al. PVP-capped silver nanoparticles as catalyst for oxidative coupling of thiols to disulfides. Chin J Catal. 2009;30: 856-858.

20. Sclafani A, Mozzanega MN, Pichat P. Effect of silver deposits on the photocatalytic activity of titanium dioxide samples for the dehydrogenation or oxidation of 2-propanol. J Photoch Photobio A-Chem. 1991;59: 181-189.

21. Sclafani A, Herrmann J. Influence of metallic silver and of platinumsilver bimetallic deposits on the photocatalytic activity of titania (anatase and rutile) in organic and aqueous media. $J$ Photochem Photobiol A-Chem. 1998;113:181-188.

22. Tada H, Teranishi K, Ito S. Additive effect of sacrificial electron donors on $\mathrm{Ag} / \mathrm{TiO}_{2}$ Photocatalytic Reduction of Bis(2-dipyridyl)disulfide to 2-Mercaptopyridine in Aqueous Media. Langmuir. 1999;15: 7084-7087.

23. Tada $\mathrm{H}$, Teranishi $\mathrm{K}$, Inubushi $\mathrm{Y}$, Ito $\mathrm{S}$. Ag nanocluster loading effect on $\mathrm{TiO}_{2}$ photocatalytic reduction of $\mathrm{Bis}$ (2-dipyridyl)disulfide to 2-mercaptopyridine by $\mathrm{H}_{2} \mathrm{O}$. Langmuir. 2000;16:3304-3309.
24. Bright RM, Musick MD, Natan MJ. Preparation and characterization of Ag colloid monolayers. Langmuir. 1998;14:5695-5701.

25. Shirtcliffe N, Nickel U, Schneider S. Reproducible preparation of silver sols with small particle size using borohydride reduction: For use as nuclei for preparation of larger particles. J Colloid Interf Sci. 1999;211:122-129.

26. Nickel U, Castell AZ, Poppl K, Schneider S. A silver colloid produced by reduction with hydrazine as support for highly sensitive surfaceenhanced Raman spectroscopy. Langmuir. 2000;16:9087-9091.

27. Pal T. Gelatin-A compound for all reasons. J Chem Educ. 1994;71: 679-681.

28. Anastas PT, Warner JC. Green Chemistry: Theory and Practice. New York: Oxford University Press; 1998.

29. Bohren CF, Huffman DR. Absorption and Scattering of Light by Small Particles. New York: John Wiley \& Sons Inc; 1998.

30. Heath JR. Size-dependent surface-plasmon resonances of bare silver particles. Phys Rev B. 1989;40:9982-9985.

31. Zhang JJ, Gu MM, Zheng TT, Zhu JJ. Synthesis of gelatin-stabilized gold nanoparticles and assembly of carboxylic single-walled carbon nanotubes/Au composites for cytosensing and drug uptake. Anal Chem. 2009;81:6641-6648.
International Journal of Nanomedicine

\section{Publish your work in this journal}

The International Journal of Nanomedicine is an international, peerreviewed journal focusing on the application of nanotechnology in diagnostics, therapeutics, and drug delivery systems throughou the biomedical field. This journal is indexed on PubMed Central, MedLine, CAS, SciSearch ${ }^{\circledR}$, Current Contents ${ }^{\circledR} /$ Clinical Medicine,

\section{Dovepress}

Journal Citation Reports/Science Edition, EMBase, Scopus and the Elsevier Bibliographic databases. The manuscript management system is completely online and includes a very quick and fair peer-review system, which is all easy to use. Visit http://www.dovepress.com/ testimonials.php to read real quotes from published authors. 